\title{
From Molecular Studies of Allergens to Development of Immunotherapy of Allergies
}

Christine YY Wai ${ }^{1}$, Nicki YH Leung ${ }^{1}$, Ka Hou Chu' ${ }^{1}$ and Patrick SC Leung ${ }^{2 *}$

${ }^{1}$ School of Life Sciences, The Chinese University of Hong Kong, Shatin, Hong Kong SAR, China

${ }^{2}$ Division of Rheumatology/Allergy, School of Medicine, University of California, USA

\begin{abstract}
Allergies are hypersensitive reactions that affect over $25 \%$ of the world population. Extensive studies have been directed to define patho-immunological mechanisms of allergy and the molecular characteristics of allergens. The emerging B cell and T cell epitope database has greatly facilitated the development of epitope-based immunotherapy that aims at modulating patients' immune responses towards a specific allergen. Modifications on the B cell epitopes reduce the affinity of allergens towards IgE while inducing immuno-tolerance as in traditional therapies utilizing native allergens. T cell epitope-based immunotherapy is considered as a safe form of therapy since the small peptide fragments cannot form cross-links with IgE. In this review, current strategies in mapping B cell and T cell epitopes are discussed. Furthermore, current progress in the translation of epitope into potential immunotherapies is illustrated with specific examples on airway and food allergies.
\end{abstract}

Keywords: Allergy; Immunotherapy; B cell epitope; T cell epitope

\section{Introduction}

Allergy is a type I hypersensitivity disease prominently influences the quality of life. Allergens can strike one through the administration of drugs, insect sting, and ingestion of food or simply inhalation, making patients hard to strictly avoid these molecules. Allergen specific immunotherapy for grass pollen allergy has been put into clinical trials since 1950s and demonstrated satisfactory therapeutic effects [1]. It therefore paves the way for extensive researches on designing different allergen specific immunotherapy and unveiling the underlying mechanisms of these therapies.

Defining the immunological mechanisms leading to allergy is crucial in designing allergen-specific immunotherapy. Sensitization of allergic individuals to allergens is initialized upon presentation of the allergen-derived peptides by the antigen presenting cells (APCs) through the major histocompatibility class II molecule (MHC class II) to naïve $\mathrm{T}$ cells, which are then activated and differentiated into type $2 \mathrm{~T}$ helper cells (Th2) (Figure 1). Cytokines such as IL-4 and IL13 from Th2 cause a class switch in B cells to produce IgE antibodies specific to the particular allergen. When the individual is exposed to the same allergen again, IgE are massively produced, cross-link with the allergen and high affinity receptor (FcERI) on mast cells and induce degranulation. Mediators such as histamine and leukotriene are released, resulting in inflammation and other associated anaphylactic responses [2].

Molecular characteristics of allergens, in particular the identification of $\mathrm{T}$ cell and $\mathrm{B}$ cell epitopes, constitute important information for the design of therapeutic regimens. T cell epitopes refer to the short peptide fragments activating Th2 via MHC class II molecules while B cell epitopes, or IgE-binding epitopes, refer to the regions recognized by IgE on the allergen. With the identification of B cell epitopes at the molecular level, hypo-allergens possessing reduced allergenicity can be constructed through the introduction of point mutations on these IgE-binding regions $[3,4]$. The lack of IgE reactivity reduces the risk of these hypo-allergens to form cross-links with IgE and thus prevents the development of allergic side effects during treatment [5]. Meanwhile, since the $\mathrm{T}$ cell epitopes are conserved, these hypo-allergens are immunogenic and thus offer therapeutic effects. Alternatively, the employment of $\mathrm{T}$ cell epitopes in immunotherapy is believed to be a potential strategy since small peptide fragments are incapable to form cross-link with IgE but yet immunogenic to modulate immune responses [6]

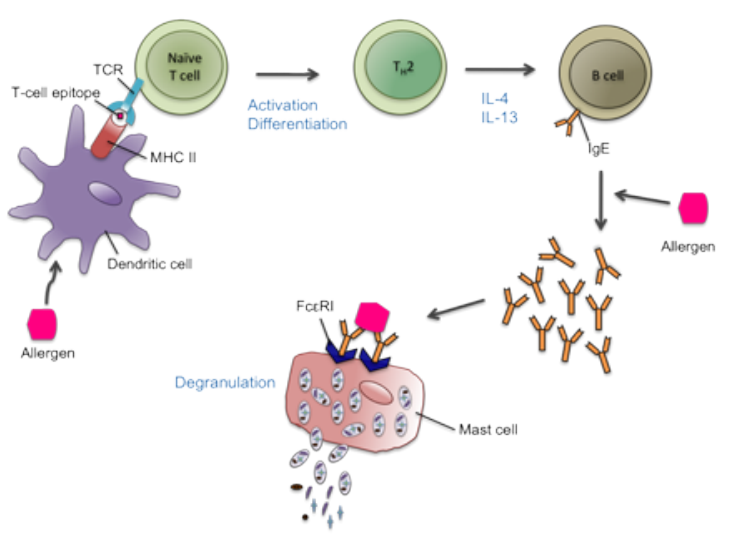

Figure 1: Pathogenesis of allergy

Upon exposure to the allergen, the APCs uptake the allergen and process it. Allergen-derived peptides are presented through MHC class II molecule to naïve T cells, which are then activated and differentiated into Th2. The release of cytokines such as IL-4 and IL-13 from Th2 causes a class switch in B cells to produce allergen-specific IgE antibodies. Upon second exposure to the same allergen, IgE are massively produced, cross-link with the allergen and FcERI on mast cells and induce degranulation. Release of mediators such as histamine and leukotriene results in inflammation and other associated immediate anaphylactic responses.

*Corresponding author: Patrick SC Leung, Division of Rheumatology/Allergy, School of Medicine, University of California, Davis, CA 95616, USA, Tel: 530-7544943; Fax: 530-754-4943; E-mail: psleung@ucdavis.edu

Received October 30, 2012; Accepted November 26, 2012; Published November 30, 2012

Citation: Wai CYY, Leung NYH, Chu KH, Leung PSC (2012) From Moleculer Studies of Allergens to Development of Immunotherapy of Allergies. J Allergy Ther 3:124. doi:10.4172/2155-6121.1000124

Copyright: ( 2012 Wai CYY, et al. This is an open-access article distributed under the terms of the Creative Commons Attribution License, which permits unrestricted use, distribution, and reproduction in any medium, provided the original author and source are credited. 


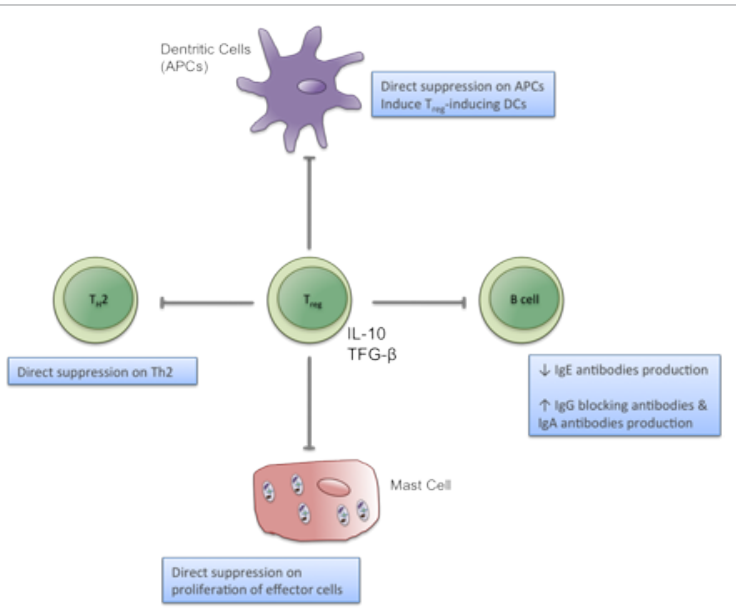

Figure 2: Role of regulatory $\mathrm{T}$ cells in immunotherapy

Regulatory $T$ cells $\left(T_{\text {reg }}\right)$ and the associated cytokines interleukin 10 (IL-10) and transforming growth factor- $\beta$ (TFG- $\beta$ ) are proposed to play roles in modulating allergic responses. They directly suppress APCs while induce $\mathrm{T}$-inducing dendritic cells (DCs), suppress Th2, inhibit IgE production, stimulate IgG blocking antibodies and IgA antibodies production, and suppress proliferation of effector cells.

Although the precise mechanisms by which epitope-based immunotherapies mediating anti-inflammatory responses are not yet thoroughly defined, they generally share similar modulating abilities on T cell and B cell responses [7]. At T cell level, the ratio of Th1 to Th2 cytokines increases following immunotherapy, suggesting a restoration in Th1/Th2 balance [8]. Regulatory T cells are also stimulated in the course and are believed to play an important role in modifying the disease through the secretion of IL-10 and TGF- $\beta$ [9] (Figure 2). At B cell level, immunotherapy suppresses IgE production whilst stimulates allergen-specific IgG that can compete with IgE for the allergen and thus serve as blocking antibodies [10].

\section{B cell Epitope-Based Immunotherapy}

\section{Mapping of $B$ cell epitopes}

Mapping of B cell epitopes is a major strategy in defining molecular characteristics of allergens. Apart from designing epitope-based therapies, epitope mapping could also help to examine the crossreactivity between phylogenetic closely related organisms [11]. Based on the molecular structure of the allergen and whether the epitopes are linear or conformational, different strategies have been developed for epitope mapping [12].

Commonstrategies include the use of inhibition assays [13] and overlapping peptides [14], but these methods are limited to the mapping of linear epitopes and the resolution is poor. Nuclear magnetic resonance (NMR) is useful in mapping conformational epitopes, but high purity of the allergen and monoclonal antibodies are needed [15]. Mapping of mimotopes is more frequently used nowadays, and it requires powerful computer algorithms to help elucidate the epitopes $[16,17]$. As computer technology is becoming more sophisticated, pure in silico methods have also been used, but requires further validation by bioassays $[18,19]$.

\section{Applications of B cell epitopes in therapy}

Severe side effects due to anaphylaxis are one of the major obstacles in immunotherapies [20]. By targeting and blocking the B cell epitopes, these side effects can be reduced by inhibiting IgE cross-linking with the goal of eliminating the subsequent allergic responses. Identification of B cell epitopes is therefore the cornerstone of a successful therapy. With the advancement of bioinformatics, $B$ cell epitopes of most of the major allergens such as peach Pru p 3 [21], latex Hev b 2 [22], shrimp Pen a 1 [14], fish Sco j 1 [23], cow's milk a-lactalbumin [24], hazelnut and walnut $11 \mathrm{~S}$ globulin [25], timothy grass pollen $\mathrm{Phl} \mathrm{p} 2$ [26], peanut Ara h 2 [27], and egg white ovalbumin [28] have been identified and "tailored" modifications of amino acid residues in the epitope resulting in reduced IgE affinity can easily be achieved by sitedirected mutagenesis. Today, based on the $\mathrm{B}$ cell epitope data, major efforts are directed to develop a safe and consistent therapeutic effect by manipulating these epitopes.

Earlier studies were carried out aiming to delete cysteine residues in the allergen to disrupt binding and thus the conformation [29]. It was shown that in the dust mite allergen Lep d 2 the two cysteine residues at the positions 72 and 77 are solely responsible for IgE binding. Although deleting them could disrupt the IgE binding region, this method can hardly be utilized for clinical use as it may cause a drastic change to the conformation. T cell epitopes might be lost and there are risks of sensitization to this new mutant [30].

The IgE binding regions of the major Parietaria pollen allergens (Par j 1 and Par j 2) were identified by Colombo et al. [31]. Based on this result, Bonura et al. [32] demonstrated the use of PCR-based site-directed mutagenesis to design hypo-allergen hybrids with three substitutions of critical amino acids for IgE binding using the Par $\mathrm{j} 1$ and Par $\mathrm{j} 2$ as a model. The altered Par $\mathrm{j} 1$ and Par $\mathrm{j} 2$ were then used to form a head-to-tail dimer (PjEDloop1) and the therapeutic effect of the dimer was investigated. It was found that PjEDloop1 had a significant decrease of binding ability to human IgE, and was able to induce IgG1 that could be potential blocking antibodies of the native allergens. PjEDloop1 still maintained an intact $\mathrm{T}$ cell epitope, which retained its capacity in splenocyte proliferation, and this might be the key to the success of using hypo-allergen to induce T cell tolerance/anergy.

Another study using the castor bean allergen Ric c 1 and Ric $\mathrm{c} 3$ as a model investigated the therapeutic potential of using peptides of altered IgE binding epitopes. Felix et al. [33] identified six IgE binding regions in Ric $\mathrm{c} 1$ or Ric $\mathrm{c}$ 3. All six IgE epitopes contained two or more glutamic acid residues. Deus-de-Oliveira et al. [3] utilized a dicarboxylic amino acid-specific chemical, the Woodward's Reagent K (WRK), to modify the carboxylic groups of glutamic acid into a ketoketenimine group. It was observed that the altered epitopes had a significant reduction in their ability to stimulate mast cell degranulation. This study provides a new approach for developing allergy therapies.

Tropomyosin is a well-studied pan-allergen among crustaceans and mollusks [34], while tropomyosins from vertebrates have not been reported to be allergenic [35] despite their relatively high sequence homology ranging from 51-58\% [36]. Reese et al. [4] constructed a hypo-allergen VR9-1 by converting 12 critical amino acids located in the five IgE epitope regions in the shrimp tropomyosin Pen a 1 previously mapped [14] into homologous sequences of the non-allergenic vertebrate tropomyosin. Results showed that VR9-1 exhibited reduced allergenic potency up to $90-98 \%$ in a humanized rat basophil leukemia cells (RBL) assay. However, when the humanized RBL were challenged with VR9-1 at higher concentrations, the mediators released were at about the same level as the native Pen a 1. The authors attributed this to the minor IgE epitopes, where under high concentration $\square$ they would also become prominent and stimulate mediator release. Hence enthusiasm for its clinical applications is markedly reduced. 
Wallmann et al. [37] demonstrated the use of a single mimotope mimicking the IgE epitope of the timothy grass pollen allergen Phl p 5 is able to down-regulate inflammation in a mouse model of allergic acute asthma. Vaccination with mimotope conjugated with keyhole limpet hemocyanin resulted in the decrease of Th2 cytokines, eosinophil counts and mucus production in mice with induced acute allergic asthma. Using these IgE epitope mimics devoid of $\mathrm{T}$ cell epitopes specifically targets B cells alone, aiming to induce IgG blocking antibodies that recognize the native allergen as a therapeutic measure. As this approach does not involve T cells, side effects related to overstimulation of $\mathrm{T}$ cells can be avoided.

Utilizing the knowledge on B cell epitopes, extensive efforts were directed to design hypo-allergenic counterparts (Table 1). This allows the conservation of conformational structure and $\mathrm{T}$ cell epitopes of the allergen, thus achieving therapeutic effect by stimulating regulatory $\mathrm{T}$ cells but not resulting in severe side effects as in conventional immunotherapies [38]. The use of mimotope opens a new pathway for allergy treatment by specifically targeting at B cells devoid of $\mathrm{T}$ cells epitopes [39]. It has the advantage of reducing possible late-phase hypersensitive response due to $\mathrm{T}$ cell stimulation. However, in some cases such as the shellfish allergen tropomyosin, mapping of a single dominant IgE epitope might be difficult due to its simple dimeric alpha-helix structure which allows extensive exposed regions for $\operatorname{IgE}$ binding. This might remain to be a major obstacle in utilizing $B$ cell epitopes as a treatment in some allergens. Nevertheless, B cell epitopes are relevant targets to reduce immediate hypersensitive response by lowering IgE affinity and thus mediator release by cross-linking of IgE on mast cells. Further efforts are needed to design immunotherapies that are persistent and long-lasting based on B cell epitopes.

\section{T cell Epitope-Based Immunotherapy}

The use of $\mathrm{T}$ cell epitope-based peptides is one of the therapeutic strategies to induce immuno-modulation effects. Delivery of $\mathrm{T}$ cell epitopes induces tolerance whilst these small-sized peptides virtually lack secondary or tertiary structures, and thus exhibit no or low IgE reactivity, making them a safe candidate in allergen-specific immunotherapies. It was proposed that immuno-tolerance is most likely to be induced by this type of treatment through the recruitment of Th1 and/or presentation of these peptides by non-professional APCs that activate regulatory $\mathrm{T}$ cells $[40]$.

\section{Mapping of T cell epitopes}

Similar to the screening of linear B cell epitopes, T cell epitopes can be revealed by proliferation response of the $\mathrm{T}$ lymphocytes upon stimulation by overlapping synthetic peptides that span the whole amino acid sequence of the target allergen. For example, peripheral blood mononuclear cells (PBMCs) from 18 peach allergic patients and peach allergen (Pru p 3) specific T cell lines from nine patients were cultured and analyzed for proliferation response in the presence of 17 overlapping peptides that spans the entire sequence of Pru p 3 [41]. Each peptide is of 10-amino acid residues long with five overlapping amino acids. One immunogenic T cell epitope, Pru p 365-380 (NAAALPGKCFVSIPYK), was identified.

Apart from using human cell lines, $\mathrm{T}$ cell epitopes are also derived from animal studies. In a Balb/c model of OVA sensitization, splenocytes were used for peptide stimulation [42] and proliferation was measured by the degree of conversion of WST-1 tetrazolium salt by the metabolically active $\mathrm{T}$ cells. Data from proliferation and cytokine (IL-4 and IFN- $\gamma$ ) production demonstrated the presence of four $\mathrm{T}$ cell-recognizing regions on OVA. These $\mathrm{T}$ cell epitopes are each of 12 amino acids long and are found on OVA regions A39R50 (AMVYLGAKDSTR), S147R158 (SWVESQTNGIIR), K263E274 (KLTEWTSSNVME) and A329E340 (AAHAEINEAGRE) respectively.

To reveal the peptide sequences naturally presented by APCs and MHC class II molecules, the major birch pollen allergen Bet $\mathrm{v} 1$ was digested by the endolysosomal extracts of dendritic cells (DCs) from four birch pollen allergy patients [43]. This resulted in the elution of 27 Bet $v$ 1-derived peptides that were of 14-28 amino acids long. 18-mer peptides were first synthesized according to the natural DCs-derived peptide sequences to stimulate $\mathrm{T}$ cell epitope-specific $\mathrm{T}$ cell lines. Another 50 overlapping 12-mer peptides spanning the full length of Bet $\mathrm{v} 1$ were also used as stimulants for Bet v 1-specific $\mathrm{T}$ cell lines. Sequences of the peptides that triggered strong proliferation were compared to the peptides generated by endolysosomal degradation as well as to known Bet v $1 \mathrm{~T}$ cell epitopes. The high resemblance suggests the reliability of traditional $\mathrm{T}$ cell epitope mapping assays.

\section{Applications of $\mathrm{T}$ cell epitopes in therapy}

Cat allergy: Studies on T cell peptide-based immunotherapy (PIT) concerning cat allergy are extensive. A preliminary study was conducted on cat allergy patients on the effects of PIT as early as in 1993 [44]. 95 cat allergy patients with positive skin prick test to cat hair, no previous immunotherapy experiences and showed at least two airway symptoms upon exposure in a cat room were included in the study. They were randomly divided into four groups, each with 22-26 patients, and received either peptide or placebo treatment (control). Patients in the treatment groups were subcutaneously injected with two 27-amino acid peptides (IPC1-KRDVDLFLT-GTPDEYVEQVAQYKALPV and IPC2 KALPVVLENARILKNCVDAKMTEEDK-E) comprising multiple $\mathrm{T}$ cell epitopes of the major cat allergen Fel $\mathrm{d} 1$. The three treatment groups received different peptide doses $(7.5 \mu \mathrm{g}, 75 \mu \mathrm{g}$ and $750 \mu \mathrm{g})$ and all groups were exposed in a room inhabited by live cats for 60 minutes after the course for allergy symptoms assessment. Patients receiving the highest peptide dose showed reduction in nasal (itchy nose or throat; runny watery nose; nasal congestion or stuffiness) and lung symptoms (wheezing in chest; tightness of chest and/or constrictive sensation in throat; shortness of breath). Ex vivo analysis also showed reduction

\begin{tabular}{|c|c|c|c|c|}
\hline Allergen & Modification & Effects & Remarks & Reference \\
\hline Lep d 2 & Deletion of 2 cysteine molecules & Significantly reduced IgE affinity & Disrupted allergen conformation & {$[29]$} \\
\hline Par j 1/ Par j 2 & Substituted 3 critical amino acids & $\begin{array}{l}\text { Reduced IgE affinity, induction of IgG blocking } \\
\text { antibodies, stimulate } T \text { cell proliferation }\end{array}$ & $\begin{array}{l}\text { Efficacy tested with a dimer of the } \\
\text { mutants }\end{array}$ & [31] \\
\hline Ric c 1/ Ric c 3 & $\begin{array}{l}\text { Alteration of glutamic acid residues in } \\
\text { epitope }\end{array}$ & $\begin{array}{l}\text { Significant reduce in ability to induce mast cell } \\
\text { degranulation }\end{array}$ & & [3] \\
\hline Pen a 1 & $\begin{array}{l}\text { Substituted } 12 \text { critical amino acids in } 5 \\
\text { epitope regions }\end{array}$ & $\begin{array}{l}\text { Reduced mediators release in a humanized RBL } \\
\text { assay }\end{array}$ & $\begin{array}{l}\text { Maximal release of mediators under } \\
\text { high concentration of mutants }\end{array}$ & [4] \\
\hline Phl p 5 & $\begin{array}{l}\text { Single mimotope peptide of an } \lg E \\
\text { epitope }\end{array}$ & $\begin{array}{l}\text { Down-regulated inflammatory response, reduced } \\
\text { Th2 cytokines }\end{array}$ & No T cells involvement & {$[37]$} \\
\hline
\end{tabular}

Table 1: Summary of different B cell epitope modification strategies and effects of modification for different allergens. 
in IL-4 production from $\mathrm{T}$ cell lines generated from peptide-treated patients compared to that generated from placebo-treated group [45], further suggesting the applicability of PIT in treating cat allergy.

Allergic symptoms arose between ten minutes and six hours after injection of the IPC1 and IPC2 were reported, possibly due to the cross-linking of IgE with these long peptides. A later study in 2002 employed 12 overlapping short peptides (16-17 amino acids long) in PIT, knowing that none of the 40 cat allergy patients developed IgEdependent early allergic responses after injection of these peptides [46]. Intradermal injections of increasing dose of peptides and at a final concentration of $90 \mu \mathrm{g}$ inhibited both early and late reactions when patients were exposed to cat and Fel d 1. Reduction in IL-4 production and enhancements in IL-10 level were observed in the peptide-treated group. Follow-up analysis provided evidence for the recruitment of Th1 as well as $\mathrm{CD} 4^{+} \mathrm{T}$ cell with suppressing/regulatory activity after such PIT, suggesting the possible underlying mechanism leading to allergic inflammation down-regulation $[47,48]$. A more detailed assessment on the cat allergen-induced nasal and bronchial reactions, and asthma/rhinitis quality of life was later performed in order to confirm the clinical efficacy of this PIT [49]. 16 patients with a history of both early- and late- phase asthmatic reactions upon cat exposure were divided into two groups and subjected to peptide or placebo blind treatments. 12 patients with only early-phase asthmatic reactions were also included for peptide treatment in an open manner. Patients who received active treatment were injected with increasing doses of peptide (total $291 \mu \mathrm{g}$ ) by intradermal injection. Patients in the open study showed significant reduction in the number of sneezes, weight of nasal discharge and nasal blockage scores when challenged with $0.1 \mathrm{ml}$ of cat allergen solution spray while patients in the blind active treatment group showed improvements in several Quality of Life outcomes (e.g. non-nose/ non-eye symptoms, nasal problems etc.). With these promising results, a peptide vaccine containing only ten of the above Fel d 1-derived peptides was already put into a phase IIa clinical trial to determine the safe and well-tolerated dosage for future clinical applications [50].

Egg allergy: Translation of T cell epitopes into PIT for clinical application has been extensive in cat allergy and bee venom allergy $[51,52]$ but is limited regarding such application on food allergies. T cells epitopes have been mapped in a number of food allergens including the cow's milk allergen as1-casein [53], peanut allergen Ara h 2 [54], peach allergen Pru p 3 [41], egg allergen ovalbumin (OVA) [42] and egg-white allergen ovomucoid (Ovm) [55]. However, investigations on the feasibility of these epitopes being utilized in PIT and the possible clinical outcome were restricted to egg allergy to date.

Using an animal model, three 15-mer peptides, each comprising one immunodominant $\mathrm{T}$ cell epitope of OVA, were injected subcutaneously in a single or cocktail manner to OVA-sensitized $\mathrm{BALB} / \mathrm{c}$ mice [56]. After a high-dose OVA challenge following active PIT, significant attenuation in systemic anaphylactic symptoms, serum histamine concentrations, OVA-specific IgE and Th2-associated cytokine levels were exhibited in the cocktail-treatment group. The peptide treatment groups also had significantly higher levels of the Th1assoicated cytokine IFN $-\gamma$, suggesting a restoration of Th $1 /$ Th 2 balance upon PIT. Furthermore, significant augmentation in both TGF- $\beta$ and FOXP3 expressions in intestine of the cocktail-treated group implies that PIT is capable of promoting $\mathrm{T}_{\mathrm{reg}}$ - associated responses.

Similar therapeutic efficacy assessment was performed on the use of Ovm T cell epitope-based therapy [57]. Sensitized BALB/c mice were orally treated with the single 15 -mer immunodominant peptide,

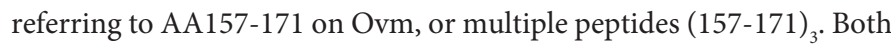
single and multiple peptide treatment groups exhibited similar Th1/ Th2 balance restoration and $\mathrm{T}_{\mathrm{reg}}$-associated response up-regulation profile as reported in the Yang et al.'s study on OVA PIT [56]. These promising results shed light on the great applicability of PIT in food allergies.

\section{Economic Impact of Allergy and Immunotherapy}

Allergy is a malady that can lead to severe anaphylaxis or even death. Immunotherapy is currently one of the best ways to gain a longterm cure. Presently, some medical organizations in the United States already provide sublingual and subcutaneous allergy immunotherapy (SLIT and SCIT respectively) [58]. The cost of SLIT depends on the number and amount of allergens included in the treatment, ranged from US\$ 960 (10 allergens, $0.6 \mathrm{ml}$ each) to US\$ 2100 (25 allergens, 1 $\mathrm{ml}$ each). On the other hand, the cost of SCIT varies from US\$ 260 to US\$2 260 per year depending on the number of weekly allergy injection visits. Although the expenses of immunotherapy might be enormous, most patients are more than willing to pay to seek for a long-lasting cure.

Apart from improving living quality, patients gain economic advantages from immunotherapy as well. In a long-term study by Ariano et al. [59], 30 Parietaria pollen allergy patients were included. 20 patients received SCIT while 10 patients received anti-allergic drugs treatment only. They were evaluated before and after the treatment for their number of specialists' visits, desensitizing injections and boxes of anti-allergic drugs. A 15\% cost reduction was observed in the second year and a significant reduction (80\%) was found three years after stopping immunotherapy.

\section{Conclusions}

Conventional allergen-specific immunotherapies using allergen extracts could induce unwanted side effects such as systemic anaphylactic response. Despite the risk of having severe side effects, allergen-specific therapies have the advantage over allergen nonspecific therapies such as anti-IgE or gene silencing in that they would not disturb our immune system by using artificial materials or manipulation but rather take advantage of the regulatory properties of the natural immune system to achieve curative effect. By specifically targeting B cell or T cell epitopes, or both, undesired side effects can be highly reduced or even ideally eliminated and the treatments can have a longer lasting effect. The major limitations in the past were the difficulties in identifying precise epitope regions and thus the earlier allergen-specific immunotherapies can only make use of native allergen extracts that have a higher risk of having unwanted side effects. Moreover, the crude extracts are hardly quantitatively or qualitatively standardized for allergenic active components. With the advancement of bioinformatics technology, sophisticated ways of mapping B cell and T cell epitopes have been developed. Preliminary studies also provide robust evidence in the therapeutic effects of $\mathrm{B}$ cell or $\mathrm{T}$ cell epitopebased treatments. The application of $\mathrm{B}$ cell and $\mathrm{T}$ cell epitopes will certainly lead us into a new era of immunotherapy. However, allergenspecific immunotherapies still have certain limitations. Epitope regions might be different for different individuals. It remains a challenge in developing a universal therapy that covers all the different epitopes from a pool of patients with heterogeneous clinical history. Moreover, an individual might be sensitized to more than one allergen and the epitope regions of many minor allergens are yet to be defined. Nevertheless, allergen-specific immunotherapies hold the hope for the future as it offers a more "natural" way of gaining therapeutic 
Citation: Wai CYY, Leung NYH, Chu KH, Leung PSC (2012) From Molecule Studies of Allergens to Development of Immunotherapy of Allergies. J Allergy Ther 3:124. doi:10.4172/2155-6121.1000124

effect compared to non-allergen specific immunotherapies. With the increasing knowledge in T cell and B cell epitopes and perhaps future technological advances in engineering these epitopes and modulation of their immune responses, allergen-specific therapies can become the most promising therapeutic regimen for allergy.

\section{References}

1. Durham SR, Walker SM, Varga EM, Jacobson MR, O'Brien F, et al. (1999) Long-term clinical efficacy of grass-pollen immunotherapy. N Engl J Med 341: $468-475$

2. Vickery BP, Scurlock AM, Jones SM, Burks AW (2011) Mechanisms of immune tolerance relevant to food allergy. J Allergy Clin Immunol 127: 576-584.

3. Deus-de-Oliveira N, Felix SP, Carrielo-Gama C, Fernandes KV, DaMatta RA et al. (2011) Identification of critical amino acids in the lgE epitopes of Ric C 1 and Ric c 3 and the application of glutamic acid as an IgE blocker. PLoS One 6: e21455

4. Reese G, Viebranz J, Leong-Kee SM, Plante M, Lauer I, et al. (2005) Reduced allergenic potency of VR9-1, a mutant of the major shrimp allergen Pen a 1 (tropomyosin). J Immunol 175: 8354-8364.

5. Holm J, Gajhede M, Ferreras M, Henriksen A, Ipsen H, et al. (2004) Allergy vaccine engineering: epitope modulation of recombinant Bet $v 1$ reduces $\lg E$ binding but retains protein folding pattern for induction of protective blockingantibody responses. J Immunol 173: 5258-5267.

6. Larché M (2011) T cell epitope-based allergy vaccines. Curr Top Microbio Immunol 352: 107-119

7. Larché M, Akdis CA, Valenta R (2006) Immunological mechanisms of allergenspecific immunotherapy. Nat Rev Immunol 6: 761-771.

8. Gafvelin G, Parmley S, Neimert-Andersson T, Blank U, Eriksson TL, et al. (2007) Hypoallergens for allergen-specific immunotherapy by directed molecular evolution of mite group 2 allergens. J Biol Chem 282: 3778-3787.

9. Ozdemir C, Akdis M, Akdis CA (2009) T regulatory cells and their counterparts: masters of immune regulation. Clin Exp Allergy 39: 626-639.

10. Jutel M, Akdis CA (2011) Immunological mechanisms of allergen-specific immunotherapy. Allergy 66: 725-732.

11. Ayuso R, Reese G, Leong-Kee S, Plante M, Lehrer SB (2002) Molecular basis of arthropod cross-reactivity: IgE-binding cross-reactive epitopes of shrimp, house dust mite and cockroach tropomyosins. Int Arch Allergy Immunol 129: $38-48$

12. Lin J, Sampson HA (2009) The role of immunoglobulin E-binding epitopes in the characterization of food allergy. Curr Opin Allergy Clin Immunol 9: 357-363.

13. Bugajska-Schretter A, Elfman L, Fuchs T, Kapiotis S, Rumpold H, et al. (1998) Parvalbumin, a cross-reactive fish allergen, contains IgE-binding epitopes sensitive to periodate treatment and $\mathrm{Ca}^{2+}$ depletion. J Allergy Clin Immunol 101: $67-74$.

14. Ayuso R, Lehrer SB, Reese G (2002) Identification of continuous, allergenic regions of the major shrimp allergen Pen a 1 (tropomyosin). Int Arch Allergy Immunol 127: 27-37.

15. Alessandri S, Sancho A, Vieths S, Mills CE, Wal JM, et al. (2012) Highthroughput NMR assessment of the tertiary structure of food allergens. PLoS One 7: e39785.

16. Bøgh KL, Nielsen $H$, Madsen CB, Mills EN, Rigby N, et al. (2012) IgE epitopes of intact and digested Ara h 1: a comparative study in humans and rats. Mol Immunol 51: 337-346.

17. Tiwari R, Negi SS, Braun B, Braun W, Pomés A, et al. (2012) Validation of a phage display and computational algorithm by mapping a conformational epitope of Bla g 2. Int Arch Allergy Immunol 157: 323-330.

18. Nair S, Kukreja N, Singh BP, Arora N (2011) Identification of B cell epitopes of alcohol dehydrogenase allergen of Curvularia lunata. PLoS One 6: e20020.

19. Maleki SJ, Teuber SS, Cheng H, Chen D, Comstock SS, et al. (2011) Computationally predicted IgE epitopes of walnut allergens contribute to crossreactivity with peanuts. Allergy 66: 1522-1529.

20. Bousquet J, Lockey R, Malling HJ (1998) Allergen immunotherapy: therapeutic vaccines for allergic diseases. A WHO position paper. J Allergy Clin Immunol 102: $558-562$
21. García-Casado G, Pacios LF, Díaz-Perales A, Sánchez-Monge R, Lombardero $M$, et al. (2003) Identification of IgE-binding epitopes of the major peach allergen Pru p 3. J Allergy Clin Immunol 112: 599-605.

22. Barre A, Culerrier R, Granier C, Selman L, Peumans WJ, et al. (2009) Mapping of IgE-binding epitopes on the major latex allergen Hev b 2 and the crossreacting 1,3 beta-glucanase fruit allergens as a molecular basis for the latexfruit syndrome. Mol Immunol 46: 1595-1604.

23. Saori Y, Ayako I, Kazuo S (2008) Elucidation of a major IgE epitope of Pacific mackerel parvalbumin. Food Chem 111: 857-861.

24. Hochwallner H, Schulmeister U, Swoboda I, Focke-Tejkl M, Civaj V, et al. (2010) Visualization of clustered IgE epitopes on alpha-lactalbumin. J Allergy Clin Immunol 125: 1279-1285.

25. Robotham JM, Hoffman GG, Teuber SS, Beyer K, Sampson HA, et al. (2009) Linear IgE-epitope mapping and comparative structural homology modeling of hazelnut and English walnut 11S globulins. Mol Immunol 46: 2975-2984

26. Padavattan S, Flicker S, Schirmer T, Madritsch C, Randow S, et al. (2009) High-affinity IgE recognition of a conformational epitope of the major respiratory allergen Phl p 2 as revealed by X-ray crystallography. J Immunol 182: 2141 2151.

27. Shreffler WG, Lencer DA, Bardina L, Sampson HA (2005) IgE and IgG4 epitope mapping by microarray immunoassay reveals the diversity of immune response to the peanut allergen, Ara h 2. J Allergy Clin Immunol 116: 893-899.

28. Mine $Y$, Rupa $P$ (2003) Fine mapping and structural analysis of immunodominant IgE allergenic epitopes in chicken egg ovalbumin. Protein Eng 16: 747-752.

29. Olsson S, van Hage-Hamsten M, Whitley P (1998) Contribution of disulphide bonds to antigenicity of Lep d 2, the major allergen of the dust mite Lepidoglyphus destructor. Mol Immunol 35: 1017-1023.

30. Pree I, Reisinger J, Focke M, Vrtala S, Pauli G, et al. (2007) Analysis of epitopespecific immune responses induced by vaccination with structurally folded and unfolded recombinant Bet $\mathrm{v} 1$ allergen derivatives in man. J Immunol 179: 5309-5316.

31. Colombo P, Kennedy D, Ramsdale T, Costa MA, Duro G, et al. (1998) Identification of an immunodominant IgE epitope of the Parietaria judaica major allergen. J Immunol 160: 2780-2785.

32. Bonura A, Passantino R, Costa MA, Montana G, Melis M, et al. (2012) Characterization of a Par j 1/Par j 2 mutant hybrid with reduced allergenicity for immunotherapy of Parietaria allergy. Clin Exp Allergy 42: 471-480

33. Felix SP, Mayerhoffer RO, Damatta RA, Verícimo MA, Nascimento VV, et al (2008) Mapping IgE-binding epitopes of Ric c 1 and Ric c 3, allergens from Ricinus communis, by mast cell degranulation assay. Peptides 29: 497-504.

34. Leung PS, Chow WK, Duffey S, Kwan HS, Gershwin ME, et al. (1996) IgE reactivity against a cross-reactive allergen in crustacea and mollusca: evidence for tropomyosin as the common allergen. J Allergy Clin Immunol 98: 954-961.

35. Ayuso R, Lehrer SB, Tanaka L, Ibañez MD, Pascual C, et al. (1999) IgE antibody response to vertebrate meat proteins including tropomyosin. Ann Allergy Asthma Immunol 83: 399-405.

36. Reese G, Ayuso R, Lehrer SB (1999) Tropomyosin: an invertebrate panallergen. Int Arch Allergy Immunol 119: 247-258.

37. Wallmann J, Epstein MM, Singh P, Brunner R, Szalai K, et al. (2010) Mimotope vaccination for therapy of allergic asthma: anti-inflammatory effects in a mouse model. Clin Exp Allergy 40: 650-658.

38. Focke-Tejkl M, Valenta R (2012) Safety of engineered allergen-specific immunotherapy vaccines. Curr Opin Allergy Clin Immunol 12: 555-563.

39. Gafvelin G (2010) Bypassing T cells using a B cell mimotope allergy vaccine. Clin Exp Allergy 40: 528-530

40. Steinman RM, Hawiger D, Nussenzweig MC (2003) Tolerogenic dendritic cells. Annu Rev Immunol 21: 685-711.

41. Tordesillas L, Cuesta-Herranz J, Gonzalez-Muñoz M, Pacios LF, Compés E et al. (2009) T-cell epitopes of the major peach allergen, Pru p 3: Identification and differential T-cell response of peach-allergic and non-allergic subjects. Mo Immunol 46: 722-728.

42. Yang M, Mine $Y$ (2009) Novel T-cell epitopes of ovalbumin in BALB/c mouse: potential for peptide-immunotherapy. Biochem Biophys Res Commun 378: 203-208. 
Citation: Wai CYY, Leung NYH, Chu KH, Leung PSC (2012) From Molecule Studies of Allergens to Development of Immunotherapy of Allergies. J AllergyTher 3:124. doi:10.4172/2155-6121.1000124

Page 6 of 6

43. Mutschlechner S, Egger M, Briza P, Wallner M, Lackner P, et al. (2010) Naturally processed T cell-activating peptides of the major birch pollen allergen. J Allergy Clin Immunol 125: 711-718.

44. Norman PS, Ohman JL Jr, Long AA, Creticos PS, Gefter MA, et al. (1996) Treatment of cat allergy with T-cell reactive peptides. Am J Respir Crit Care Med 154: 1623-1628.

45. Marcotte GV, Braun CM, Norman PS, Nicodemus CF, Kagey-Sobotka A, et al. (1998) Effects of peptide therapy on ex vivo T-cell responses. J Allergy Clin Immunol 101: 506-513.

46. Oldfield WL, Larché M, Kay AB (2002) Effect of T-cell peptides derived from Fel d 1 on allergic reactions and cytokine production in patients sensitive to cats: a randomised controlled trial. Lancet 360: 47-53.

47. Alexander C, Ying S, B Kay A, Larché M (2005) Fel d 1-derived T cell peptide therapy induces recruitment of CD4+ CD25+; CD4+ interferon-gamma+ T helper type 1 cells to sites of allergen-induced late-phase skin reactions in catallergic subjects. Clin Exp Allergy 35: 52-58.

48. Verhoef A, Alexander C, Kay AB, Larché M (2005) T cell epitope immunotherapy induces a CD4+ T cell population with regulatory activity. PLoS Med 2: e78.

49. Alexander C, Tarzi M, Larché M, Kay AB (2005) The effect of Fel d 1-derived T-cell peptides on upper and lower airway outcome measurements in catallergic subjects. Allergy 60: 1269-1274.

50. Worm M, Lee HH, Kleine-Tebbe J, Hafner RP, Laidler P, et al. (2011) Development and preliminary clinical evaluation of a peptide immunotherapy vaccine for cat allergy. J Allergy Clin Immunol 127: 89-97.

51. Müller U, Akdis CA, Fricker M, Akdis M, Blesken T, et al. (1998) Successfu immunotherapy with T-cell epitope peptides of bee venom phospholipase A2 induces specific T-cell anergy in patients allergic to bee venom. J Allergy Clin Immunol 101: 747-754

52. Fellrath JM, Kettner A, Dufour N, Frigerio C, Schneeberger D, et al. (2003) Allergen-specific T-cell tolerance induction with allergen-derived long synthetic peptides: results of a phase I trial. J Allergy Clin Immunol 111: 854-861.

53. Ruiter B, Trégoat V, M'rabet L, Garssen J, Bruijnzeel-Koomen CA, et al. (2006) Characterization of $T$ cell epitopes in alphas1-casein in cow's milk allergic atopic and non-atopic children. Clin Exp Allergy 36: 303-310.

54. Prickett SR, Voskamp AL, Dacumos-Hill A, Symons K, Rolland JM, et al. (2011) Ara $\mathrm{h} 2$ peptides containing dominant CD4+ T-cell epitopes: candidates for a peanut allergy therapeutic. J Allergy Clin Immunol 127: 608-615.

55. Mizumachi K, Kurisaki J (2003) Localization of T cell epitope regions of chicken ovomucoid recognized by mice. Biosci Biotechnol Biochem 67: 712-719.

56. Yang M, Yang C, Mine $Y$ (2010) Multiple T cell epitope peptides suppress allergic responses in an egg allergy mouse model by the elicitation of forkhead box transcription factor 3- and transforming growth factor-beta-associated mechanisms. Clin Exp Allergy 40: 668-678.

57. Rupa P, Mine Y (2012) Oral immunotherapy with immunodominant T-cell epitope peptides alleviates allergic reactions in a Balb/c mouse model of egg allergy. Allergy 67: 74-82.

58. Seiberling K, Hiebert J, Nyirady J, Lin S, Chang D (2012) Cost of allergy immunotherapy: sublingual vs subcutaneous administration. Int Forum Allergy Rhinol.

59. Ariano R, Berto P, Tracci D, Incorvaia C, Frati F (2006) Pharmacoeconomics of allergen immunotherapy compared with symptomatic drug treatment in patients with allergic rhinitis and asthma. Allergy Asthma Proc 27: 159-163. 